\title{
Contratos de Terceirização De Manutenção Industrial Modalidade Risco: Análise das Expectativas do S etor Industrial e dos Provedores de Serviços
}

\section{RISK BASED THIRD PARTY MAINTENANCE CONTRACTS: ANALYZING EXPECTATIONS OF THE INDUSTRIAL SECTOR AND SERVICE PROVIDERS}

ALEXANDRE LINHARES

Doutor em Pesquisa Operacional. Instituto Nacional de Pesquisas Espaciais. Escola Brasileira de Administração Pública e de Empresas. Fundação Getúlio Vargas. Praia de Botafogo 190/509 - Rio de Janeiro - RJ - CEP 22250-900

E-mail: linhares@fgv.br

PAULO CERQUEIRA GARCIA Mestre em Gestão Empresarial, Fundação Getulio Vargas. Escola Brasileira de Administração Pública e de Empresas. Fundação Getulio Vargas. Praia de Botafogo 190/509 - Rio de Janeiro - RJ - CEP 22250-900. E-mail: paulo.cerqueira@br.abb.com 


\section{RESUMO}

O objetivo deste trabalho é avaliar as formas de contratação de manutenção industrial praticadas no Brasil e identificar elementos que devem ser considerados na elaboração de um contrato baseado em performance, com remuneração variável e cláusulas de risco, sob a ótica das indústrias e dos provedores de serviço. A metodologia se baseia em análise dos resultados de pesquisa de campo por meio de levantamentos por questionário realizados com os principais gestores de manutenção de grandes grupos industriais e com os executivos das empresas prestadoras de serviço de manutenção industrial. Após uma ordenação inicial das causas percebidas dos problemas correntes, o trabalho propõe uma lista de fatores críticos de sucesso para um contrato de manutenção por performance. Com a identificação e implementação desses elementos num novo modelo de contrato de risco de manutenção, acredita-se ser possível minimizar os problemas comerciais e operacionais que atualmente representam obstáculos ao sucesso da terceirização da manutenção em plantas industriais, particularmente no Brasil. O estudo é de especial interesse para outras economias emergentes em que contratos de manutenção na modalidade risco estejam gradualmente sendo implantados.

\section{PALAVRAS-CHAVE}

Gestão da manutenção; Supply chain management; Análise de risco.

\section{ABSTRACT}

The objective of this paper is to evaluate the forms of industrial maintenance contract currently practiced in Brazil and to identify elements that must be considered in the elaboration of a contract based on performance, with variable remuneration and clauses concerning risk, under the perspective of industries and service suppliers. The methodology is based on analysis of the results of research through surveys by questionnaire, carried through to the 
key managers of maintenance of large industrial groups and with executives of the companies providing industrial maintenance service. After an initial sequencing of the perceived causes for current problems, the work considers a list of critical factors of success for a performance based maintenance contract. With the identification and implementation of these elements in a new risk-based maintenance contract model, it may be possible to minimize commercial and operational problems that currently represent obstacles to success to the outsourcing of maintenance in industrial plants, particularly in Brazil. The study it is of special interest for other emergent economies where maintenance contracts of the risk modality are gradually being implanted.

\section{KEYWORDS}

Maintenance management; Supply chain management; Risk analysis.

\section{INTRODUÇ Ã O}

Para muitos setores industriais a eficiência de sua manutenção é um elemento crucial na performance geral. Historicamente se pode perceber um gradual processo de terceirização na manutenção, com três grandes momentos ainda encontrados nas organizações industriais: inicialmente, a forma de contratação de empresas de manutenção foi chamada de empreiteirização, na qual se contratava puramente a mão-de-obra direta, na grande maioria das vezes sem qualquer exigência de qualificação; numa segunda fase, a indústria passou a desenvolver contratos por serviços específicos (por exemplo pintura industrial, montagem de andaimes, reparos de equipamentos etc.); e, principalmente a partir da década de 9o, surgiu a forma de contratação global da manutenção, pela qual se transferiam para uma empresa especializada todas as atividades de manutenção da planta industrial e seus recursos correspondentes.

Nos modelos atuais de contratação de manutenção (que podem ser estimados como formas híbridas entre práticas passadas e práticas emergentes), o fornecedor de serviços vivencia um período transitório de grande oscilação, em que deve participar de um mercado que demanda contratos desde venda de taxahora ("homem-hora"), que é fundamentalmente a execução de serviços por administração, até contratos que pretendem ser os precursores dos novos tempos, incluindo modelos de performance e risco.

A modalidade performance e risco é relativamente nova no mercado mundial de manutenção industrial, não existindo muitos padrões de referência. Esse mercado de manutenção consome boa parte dos 20 bilhões de dólares anuais estimados 
para os negócios B2B especializados, mundialmente, de acordo com pesquisas britânicas (SCHLEGELMILCH e colaboradores, I992; HILL, I990). A relação histórica, antagônica, dos interesses entre cliente e fornecedor permanece como um importante paradigma a ser transposto. Baseando-se na história do relacionamento comercial entre as duas entidades, em que sempre prevaleceu o conceito de um jogo de soma zero, pode-se avaliar a dificuldade para que se alcance esse alinhamento dos objetivos.

O processo de maturação desse modelo de performance exige mudanças culturais por parte de quem contrata e de quem fornece. A mesma empresa que há décadas vem fornecendo serviços baseados em mão-de-obra pode chegar a cobrar valores excessivos em situações de emergência ou perde dinheiro em licitações. Precisa, portanto, mudar sua própria cultura. Entretanto, como fazer essa transição na medida necessária se os gestores são os mesmos, as equipes de trabalho são as mesmas, e, para complementar, os clientes também são os mesmos? É fundamental que as expectativas sobre os novos modelos de negócio estejam alinhadas.

Existem, portanto, dificuldades para que se alcance excelência no modelo de risco, seja pelo despreparo das indústrias, seja pela resistência dos fornecedores em adotar essa forma de trabalho (fantasma da possibilidade real de perdas financeiras em contratos), em função de sua ineficiência e/ou incompetência operacional. Como resultado da pressão que essa onda exerce (provocada pela grande demanda), permanece a dúvida: há condições de consolidar no Brasil a modalidade risco baseado em performance operacional como o padrão de contratação de serviços de manutenção?

O objetivo deste trabalho é estudar o mercado de terceirização da manutenção industrial, na medida em que essas práticas da modalidade risco se difundem por uma economia emergente como o Brasil, identificando os pontos correntes mais importantes que devem ser considerados na contratação desses serviços, que privilegiem processos cooperativos, do tipo "ganha-ganha”. É possível que, no estágio atual de maturidade industrial brasileira, nem os clientes industriais tenham conhecimento das principais variáveis de risco quando contratam serviços especializados de manutenção, nem os fornecedores de serviço conheçam ou procurem conhecer essa modalidade, que pode ajudar a indústria a se concentrar mais exclusivamente em suas core competencies. Para iniciar a análise, vamos discutir melhor o conceito de performance nos contratos de manutenção.

\section{PERFORMANCE NOS CONTRATOS DE MANUTENÇÃO}

Organizações operam atreladas a inúmeras práticas e conceitos implícitos que moldaram sua história. Contudo, algumas dessas práticas atrapalham sua 
capacidade de melhorar continuamente a produtividade. Podemos chamar tais práticas e conceitos disfuncionais de "obstáculos" ou "barreiras" à melhoria da performance na organização. Uma prática disfuncional que data de Taylor é a percepção pelos funcionários de que a medição é ameaçadora. Esse paradigma impede a implantação criativa de processos de medição de performance e é geralmente baseado em uma realidade subjetiva, não fundamentada em evidências históricas. Essa dificuldade de entendimento e colocação de barreiras também é abordada nos estudos de Martin (I997) e Normann (I99I), principalmente em função do alto teor invasivo na cultura da indústria e das avaliações e medições de performance. Martin (I997) categoriza os contratos segundo critérios operacionais e de retenção de conhecimento. Nessa linha, os contratos são divididos em três tipos.

- Pacote de Serviços - mais utilizados, o cliente retém todo o conhecimento e atua como integrador das atividades, exercendo completo controle sobre os resultados. Pode-se admitir que exige um bom conhecimento do serviço por ambas as partes e que representa uma complexidade média, pois o foco principal do fornecedor é atingir objetivos por meio de ferramentas de execução. O nível de relacionamento cliente-fornecedor é mínimo, pois os resultados da contratação podem ser estabelecidos e controlados em documentos contratuais. A base de conhecimento permanece quase que integralmente com a indústria contratante

- Performance - com base em indicadores de resultados preestabelecidos (metas de performance), fornecedor e indústria assumem responsabilidades compartilhadas, e o sucesso do contrato de manutenção depende do comprometimento que as empresas tenham com esses resultados. A complexidade do contrato é alta, principalmente pelos conflitos de interesse estabelecidos e pelos diversos indicadores de performance definidos para avaliar o resultado da contratação. O relacionamento cliente-fornecedor deve ser estreito e, em função dos esforços necessários para que o contrato de performance tenha sucesso, Martin (I997) sugere ainda que as empresas devam possuir um relacionamento de longo prazo (no mínimo entre I5 e 30 anos). O nível de retenção de conhecimento, da mesma forma que as responsabilidades, é compartilhado e, portanto, é significativamente maior que no pacote de serviços.

- Facilitador - pode ser entendido como uma evolução do contrato de performance, é um tipo de contrato em que o fornecedor é responsável integral pelo resultado a ser alcançado. O contratante paga pelo produto final, tal como o aumento da produtividade da indústria, comprometendo-se a dar apoio logístico, por exemplo. O nível de complexidade do contrato não é tão alto quanto no modelo de performance, visto que o fornecedor assume as 
responsabilidades pelo planejamento e execução das atividades. O relacionamento cliente-fornecedor deve ser máximo, pois o cliente deve reconhecer na empresa de serviços toda a capacidade tecnológica e o comprometimento para assumir as tarefas estratégicas envolvidas. A retenção do conhecimento é do fornecedor, e o cliente transfere, na maioria das vezes, esse conhecimento de manutenção da indústria para o fornecedor, ao longo dos anos de contrato.

Historicamente, essa divisão de contratos parece estar migrando de pacotes de serviços para performance e finalmente para o modelo facilitador. Partindo de um ponto de vista meramente econômico, os formatos performance e facilitador são muito mais interessantes, mas a contratação por pacotes de serviços pode, às vezes, ser a mais aplicável. Adicionalmente, para aplicarmos performance, por exemplo, não existem parâmetros claros para definir como um cliente pode ser analisado de forma que o fornecedor selecione o modelo mais aplicável e quais os riscos envolvidos. Seguindo a mesma linha de pensamento, não existe um formato padrão para um contrato ser estendido, ampliado ou, alternativamente, rompido em função de severas perdas ou quebra de expectativas (MARTIN, I997).

Quando muitas informações não estão disponíveis ou não são consistentes para o início do processo de contratação com formas de contratos mais avançadas, é recomendável optar-se pelo modelo de contratação mais tradicional, baseado em pacotes de serviços. Posteriormente, quando os princípios de manutenção estiverem propriamente estabelecidos, a demanda por uma manutenção mais previsível e ousada poderá ser razão natural para que seja atualizado o modelo de pacote de serviços para o contrato por performance. Martin (I997) estima que, para o estabelecimento de um contrato de performance, fazse necessário um longo período de relacionamento entre cliente e fornecedor (mais de I5 anos), devido ao nível de dedicação que é necessário e ao nível de confiança que deve ser gradualmente construído entre as partes.

Invariavelmente, a percepção do risco num processo de contratação de serviços por parte dos fornecedores tende a ser menor que por parte dos compradores, principalmente motivados pelo impulso de realizar a venda. Isso se reflete em outras partes da economia (KAHNEMAN e TVERSKY, 2000). Reduzir esse descompasso deve ser o objetivo dos bons negociadores de contratos de manutenção por performance e risco. Esse gradual ajuste de foco, por certo, se revelará importante fonte de melhoria na comunicação entre as empresas, no próprio serviço fornecido, e terminará por trazer um aumento de vantagem competitiva (MITCHELL, I998).

Caso, durante o processo de negociação de um contrato de longo prazo com cláusulas de performance e remuneração variável, a distribuição do risco entre 
as duas empresas não seja claramente identificada, ou fique evidente que seja injusta (por exemplo, uma das partes não perceba o risco ou seja obrigada a aceitar uma situação assimétrica em função do poderio econômico da outra parte ou surjam pressões de concorrência etc.), disputas judiciais podem tornar-se inevitáveis (WIDEMAN, I992). Portanto, uma efetiva e equânime divisão de riscos deve ser processada, de maneira que se estabeleça uma relação sadia de longo prazo e que sejam evitadas frustrações que esvaziarão o entusiasmo inicial e as boas intenções das partes envolvidas.

Como são então as expectativas dos provedores de serviço e dos industriais em relação aos contratos de risco? Essa questão é especialmente relevante em economias emergentes como a do Brasil, nas quais não há ainda ampla aceitação de tais contratos, amplo uso de ferramentas de análise de risco e nem relações industriais de longo prazo.

\section{PLANEJAMENTO dA pesquisa}

Os elementos escolhidos para participar desta pesquisa foram os principais gestores, representantes dos dois grupos de interesse envolvidos: indústrias (de base e de transformação) e prestadores de serviço. Foram enviados 4I7 questionários, e retornaram I3 8 dos adequados para utilização, o que representa $35 \%$ do total enviado e que pode ser considerado representativo para os objetivos da pesquisa, além de garantir consistência estatística com intervalo de confiança de $95 \%$.

Foram identificadas em testes piloto algumas variáveis de sucesso necessárias para estabelecimento de um modelo bem-sucedido de contratação de manutenção com cláusulas de risco, algumas antagônicas em relação às variáveis de fracasso, outras ligadas à inovação ou à percepção do indivíduo sobre o que é risco ou análise de risco e sobre modelos de contrato de performance com divisão de ganhos e perdas financeiras.

Os dados foram coletados por meio de pesquisa de campo, por meio da aplicação de um questionário do tipo fechado (perguntas com escolha direcionada), que foi estruturado em três partes distintas: diferenciação e categorização do público pesquisado, análise dos modelos de contratação praticados no mercado de terceirização da manutenção industrial e discussão dos fatores críticos de sucesso para que um contrato de manutenção com cláusulas de risco baseadas em performance alcance seus principais objetivos. Esses assuntos foram divididos em sete blocos, descritos a seguir. 


\section{ANÁLISE E INTERPRETAÇÃO DOS DADOS}

\subsection{BLOCO 1 - CATEGORIZAÇÃO DOS PARTICIPANTES}

Observa-se no gráfico de distribuição dos pesquisados (Gráfico I) que, entre as empresas participantes da pesquisa do setor industrial, os segmentos Químico (เ9\%), Petróleo e Gás (เ०\%) e Papel e Celulose (9\%) são os mais representativos na pesquisa. Coincidentemente, esses segmentos representam, no período recente, a principal demanda por contratos no modelo risco baseado em performance.

\section{GRÁFICO I}

\section{DISTRIBUIÇÃO DOS ENTREVISTADOS}

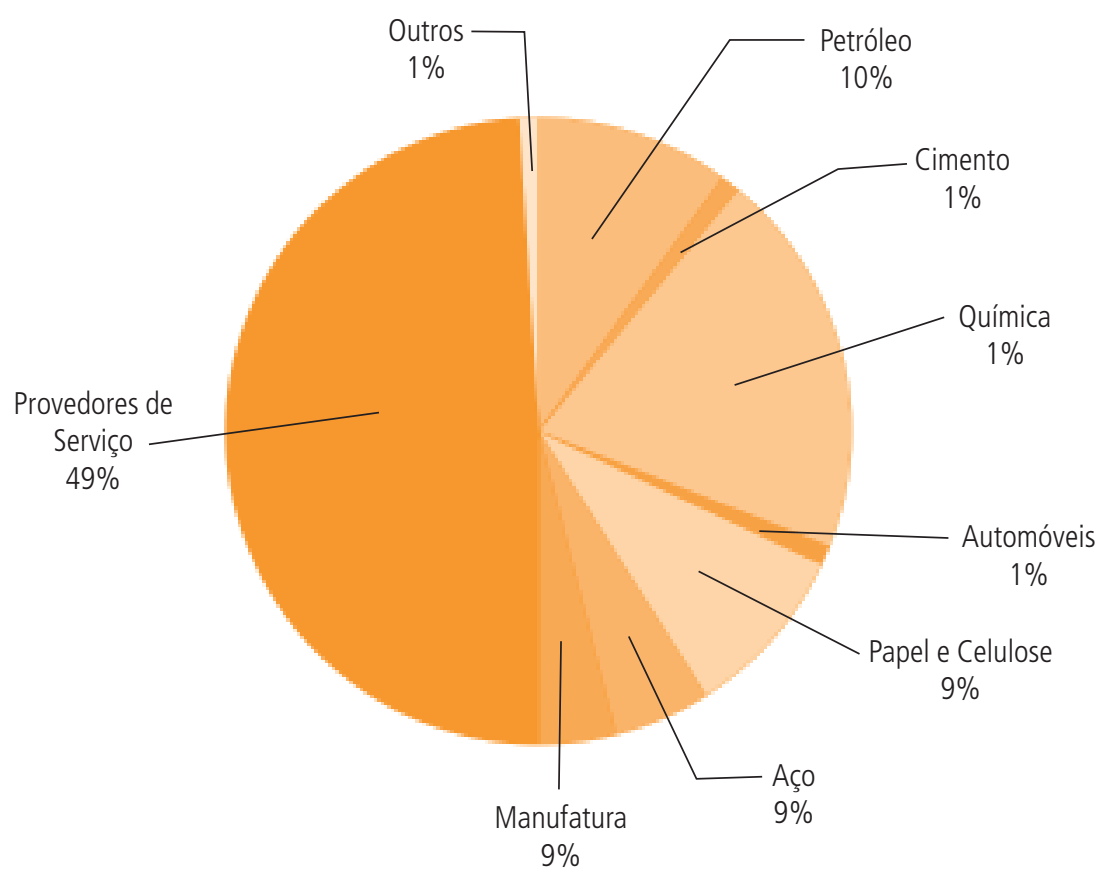

O Gráfico 2 apresenta e distribui o grupo de empresas às quais os entrevistados pertencem, segundo o faturamento da planta industrial ou do grupo controlador correspondente. Nesse gráfico, já se constata uma diferenciação entre o porte financeiro das empresas prestadoras de serviço (em que o grupo mais representativo situa-se com faturamento entre 50 e 500 milhões de reais por ano) e as indústrias em geral, cuja maioria possui faturamento superior a I bilhão de reais por ano. 


\section{GRÁFICO 2}

\section{ESTRATIFICAÇÃO POR FATURAMENTO DAS EMPRESAS}

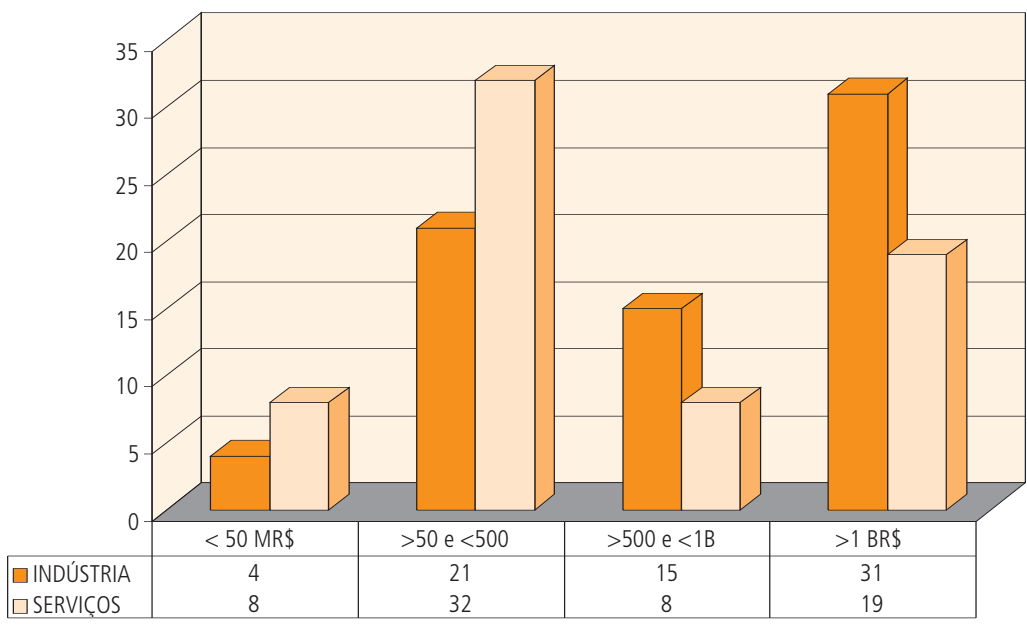

O Gráfico 3 revela o alto teor de utilização de mão-de-obra intensiva pelas empresas de serviços, setor que possui, na sua grande maioria (5I pesquisados), empresas com total de mão-de-obra própria situado entre I.000 e Io.000 funcionários. Por outro lado, as indústrias dividem-se proporcionalmente entre empresas com menos de I.000 funcionários e entre I.০०० e I0.০००.

\section{GRÁFICO 3}

\section{ESTRATIFICAÇÃO POR NÚMERO DE FUNCIONÁRIOS}

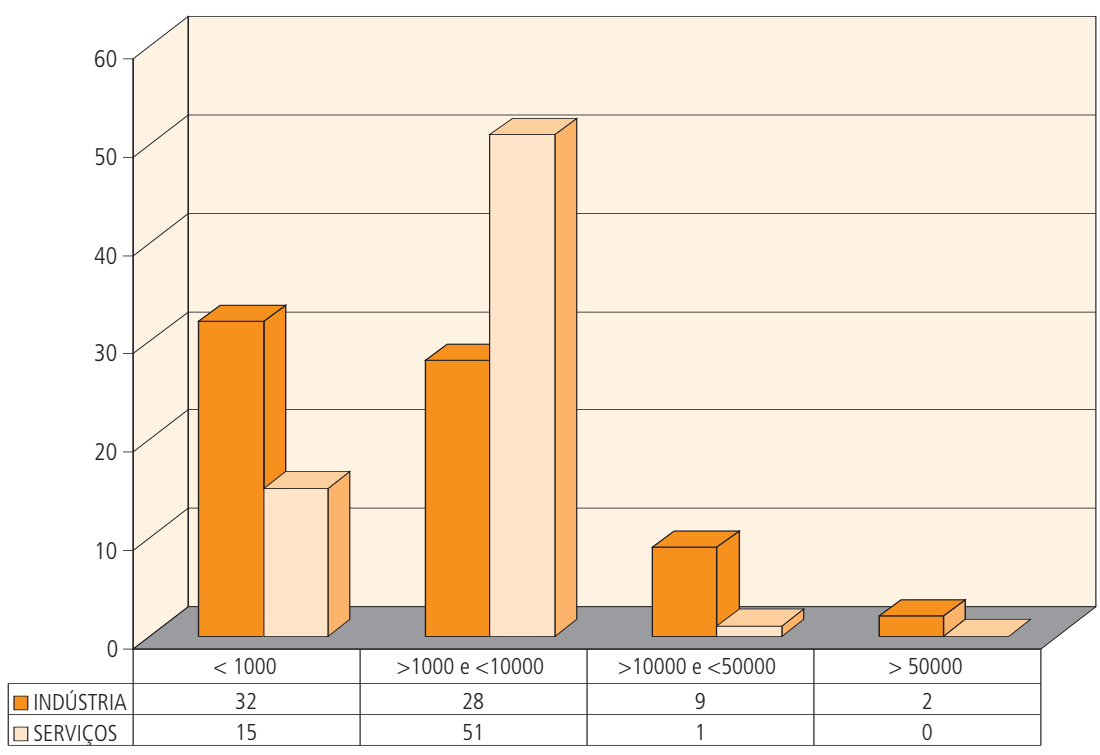


Uma das questões teve o objetivo de confirmar que o mercado de manutenção industrial (compradores e fornecedores) entende que a contratação por performance com remuneração variável é uma forma perfeitamente aplicável. O resultado obtido ratificou as expectativas, pois I0०\% dos entrevistados do setor de serviços e $96 \%$ dos representantes das indústrias responderam que concordam com a aplicação desse modelo.

Quando se procurou identificar o perfil do entrevistado ao ser submetido a situações ou possibilidades de risco financeiro, o resultado não confirmou as observações de Raftery (I994) com relação ao comportamento do gestor em ambiente de risco, apesar de ser viável considerar a possibilidade de alguma tendência na resposta (como uma auto-avaliação em Neutralidade a Risco, quando na verdade o entrevistado tende a apresentar aversão).

A grande maioria dos entrevistados enquadra-se em posição de neutralidade a risco, apesar de uma boa parcela considerar-se tomadora de risco (I5\% entre as indústrias e $25 \%$ entre os prestadores de serviço). Apesar de não poder ser comparado ao grupo de neutralidade, percebe-se que um pouco menos de I०\% de cada setor considera-se no grupo de aversão a risco.

\subsection{BLOCO 2 - AVALIAÇÃO HISTÓRICA}

O objetivo do primeiro conjunto de questões foi avaliar os aspectos relacionados aos contratos de manutenção nos últimos cinco anos. Portanto foram levantadas questões como nível de atendimento e qualidade de serviço. Dentro da parte superior da escala (Bom e Muito Bom), o aspecto melhor auto-avaliado pelos entrevistados do setor de serviços foi o nível de atendimento em linhas gerais, com $63 \%$ considerando Bom. Segundo os representantes da indústria, a melhor avaliação foi para o item de cumprimento dos itens de contrato (o fornecedor entrega os serviços comprometidos na fase de negociação). Esse item teve a preferência de $42 \%$ dos entrevistados do setor industrial, o que já revela um distanciamento entre o que cada um dos grupos avalia como ponto positivo.

Considerando as principais avaliações negativas (Ruim e Muito Ruim), o setor de serviços e as indústrias aparentemente concordaram que o ponto mais fraco é a política de remuneração salarial praticada pelas empresas prestadoras de serviço (34\% entre serviços e $37 \%$ entre indústrias). É importante verificar essa coincidência, que reflete o nível de motivação constatado dentro das equipes que, efetivamente, conduzem os contratos para o sucesso. Complementando a análise desenvolvida acima, foi situado o principal ou principais modelos de contratos mais utilizados, segundo critérios de tipo de contrato e responsabilidade pela gestão e execução das tarefas de manutenção. O Gráfico 4 apresenta o resultado comparativo em relação ao tipo de contrato considerando a forma de pagamento como fator diferenciador de tipo. 


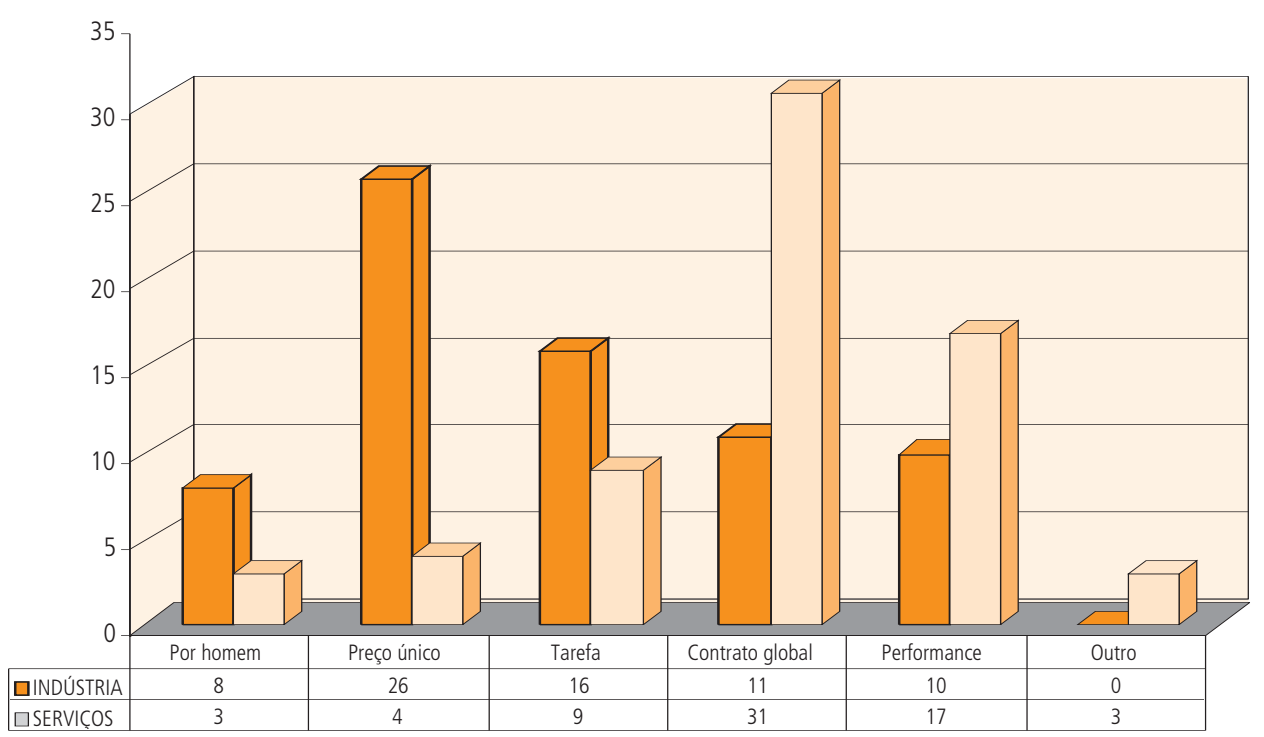

Observa-se uma diferença muito grande na avaliação da indústria e do segmento de prestação de serviços, o que é de fácil esclarecimento. Como a pesquisa envolveu as principais empresas de cada setor, a avaliação dos prestadores apresenta o cenário em que as grandes empresas de manutenção industrial estão inseridas. Essas empresas envolvem-se, atualmente, na sua maioria - 71\% -, em contratos globais de manutenção ou contratos especialistas de performance. Entretanto, o mercado ainda demanda, significativamente $-48 \%$-, modelos de contrato tradicionais (Mão-de-obra e por Preço Unitário - PU). Essa defasagem é reveladora e expressa o grande nicho potencial de mercado em que as empresas de grande porte no segmento prestação de serviços de manutenção da economia emergente brasileira ainda não atuam, principalmente supondo que uma grande parte dessa contratação por preço unitário já esteja migrando ou migrará para modelos de performance.

\subsection{BLOCO 3 - PROCESSO ATUAL DE ESCOLHA DO FORNECEDOR}

Este bloco procura analisar, sob a perspectiva dos dois conjuntos em estudo, o processo de escolha e decisão de contratação das empresas. Inicialmente foi requisitado aos entrevistados indicar os três fatores mais representativos no processo de decisão e escolha da empresa prestadora de serviços. 


\section{GRÁFICO}

\section{FATORES DECISIVOS NA ESCOLHA DO FORNECEDOR}

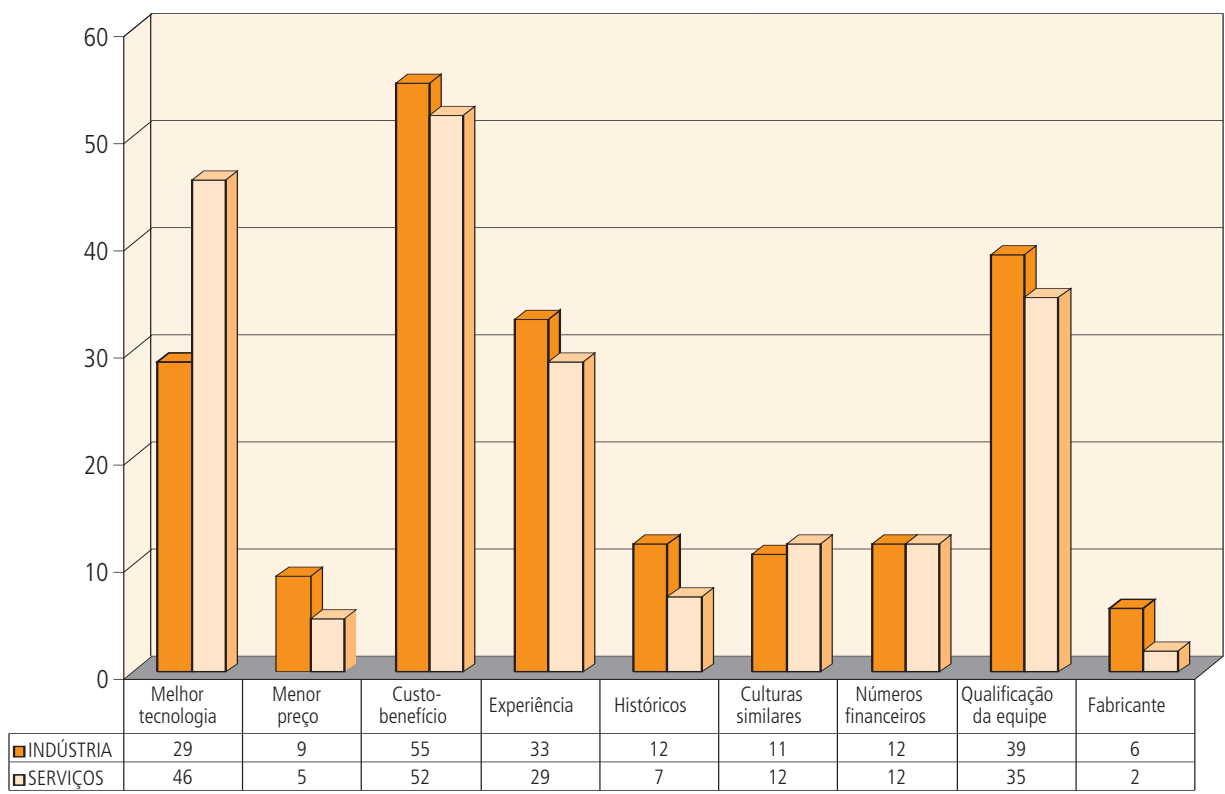

Indústria e serviços concordam quanto ao principal item para a escolha do aliado estratégico: aquele cujas soluções de modelo apresentem a melhor relação custo $\mathrm{x}$ benefício, proporcionando por conseqüência a maior produtividade média para o cliente. Os outros três são a qualificação da mão-de-obra do fornecedor, a tecnologia de manutenção oferecida e a experiência anterior em contratações dessa natureza. Esse resultado confirma o estudo de Stuart (1998), que aponta a tecnologia empregada e a experiência anterior como fatores preponderantes na escolha de empresas segundo o novo modelo de serviços de manutenção, baseado em performance. Yorke (I990), por sua vez, afirma que a experiência e as habilidades comprovadas para a equipe das empresas de serviços representavam fator principal de escolha na compra de pacotes de serviços. Isso parece demonstrar que na economia emergente brasileira ainda não há a maturidade necessária para uma precisa avaliação de experiência e habilidades comprovadas.

Os fatores menos importantes, segundo os entrevistados, derrubam algumas crenças fortemente estabelecidas dentro do segmento industrial: a importância dos fatores "menor preço" e que a empresa seja "fabricante de equipamentos". Essas características estão muito mais ligadas ao conceito tradicional de contratação de serviços que ao moderno conceito de performance. Oliva e Kallengerg (2003) demonstram que não basta ser fabricante de produtos para ganhar automática habilitação no segmento de serviços. 


\subsection{BLOCO 4 - CASOS DE SUCESSO E FRACASSO}

Observando a experiência de cada entrevistado, com base em casos e vivências pessoais de sucesso e insucesso (histórias de contratações de cada empresa ou do mercado industrial em que o entrevistado se insere), foi solicitado que o entrevistado escolhesse - de uma lista detalhada - três fatores que tenham contribuído para cada um dos exemplos.

Para os casos classificados como insucesso, que podem ter levado ao rompimento de contratos e decepção para as empresas envolvidas, os cinco fatores que mais contribuíram foram os seguintes:

- Segundo a perspectiva de quem contrata: falha na definição de metas e indicadores (acordos pouco claros que permitem diferentes interpretações); erro na formação de preços; utilização de mão-de-obra de baixa qualidade; decepção do cliente em função de o prestador de serviços não conseguir atender às expectativas criadas durante $a$ fase de negociação; pouca inovação tecnológica aplicada pelo fornecedor no contrato (provavelmente motivada pela ausência de remuneração variável baseada em performance).

- Segundo a perspectiva de quem fornece: decepção do cliente porque o fornecedor não entregou o que prometeu; preço inadequado; pouca inovação tecnológica; interferência constante do cliente no gerenciamento do contrato, impondo formas de atuação e cultura técnica e organizacional; falha na definição de metas e indicadores.

Dos cinco fatores críticos que contribuíram para o fracasso dos contratos de manutenção, nota-se que os dois grupos concordam em quatro, apesar de aparecerem com uma ordenação diferente em função de suas distintas perspectivas. O único fator discordante, na visão da indústria, é o emprego de mão-de-obra deficiente por parte dos fornecedores e, segundo o prestador de serviços, o outro fator está relacionado à pouca habilidade dos clientes em negociar e conduzir os contratos por meio de monitoramento e controle dos resultados. Segundo os fornecedores, os clientes tendem a interferir no gerenciamento da rotina e esse fator contribui significativamente para o insucesso do contrato.

A indústria distribui suas preferência entre diversos fatores de sucesso, dando para dois deles um destaque especial: a previsão dos problemas e situações de contingência, por meio de bases contratuais corretamente discutidas previamente (análises de risco). Os representantes de serviços, na mesma linha, apontam somente a previsibilidade de problemas como fator crítico de sucesso, distribuindo os demais sem desvios significativos. 


\subsection{BLOCO 5 - CONTRATO DE MANUTENÇÃO IDEAL}

Este bloco de questões procurou analisar o modelo ideal de contrato de manutenção, segundo os entrevistados. O bloco divide-se em três questões: analisa o prazo ideal de contrato, testa qual a forma de remuneração por performance é percebida como ideal e procura descobrir o formato que melhor se aplica para um contrato de manutenção por performance, se especialista (uma parte da manutenção) ou global (terceirização da manutenção como um todo). Os dois grupos consideram o prazo mínimo de três anos $(65 \%$ na indústria e $52 \%$ do setor de fornecedores de serviços). O setor serviços ainda possui uma parcela significativa que considera o prazo ideal mínimo de cinco anos (33\%).

\section{GRÁFICO 6}

\section{FORMA DE REMUNERACÃO VARIÁVEL POR PERFORMANCE}

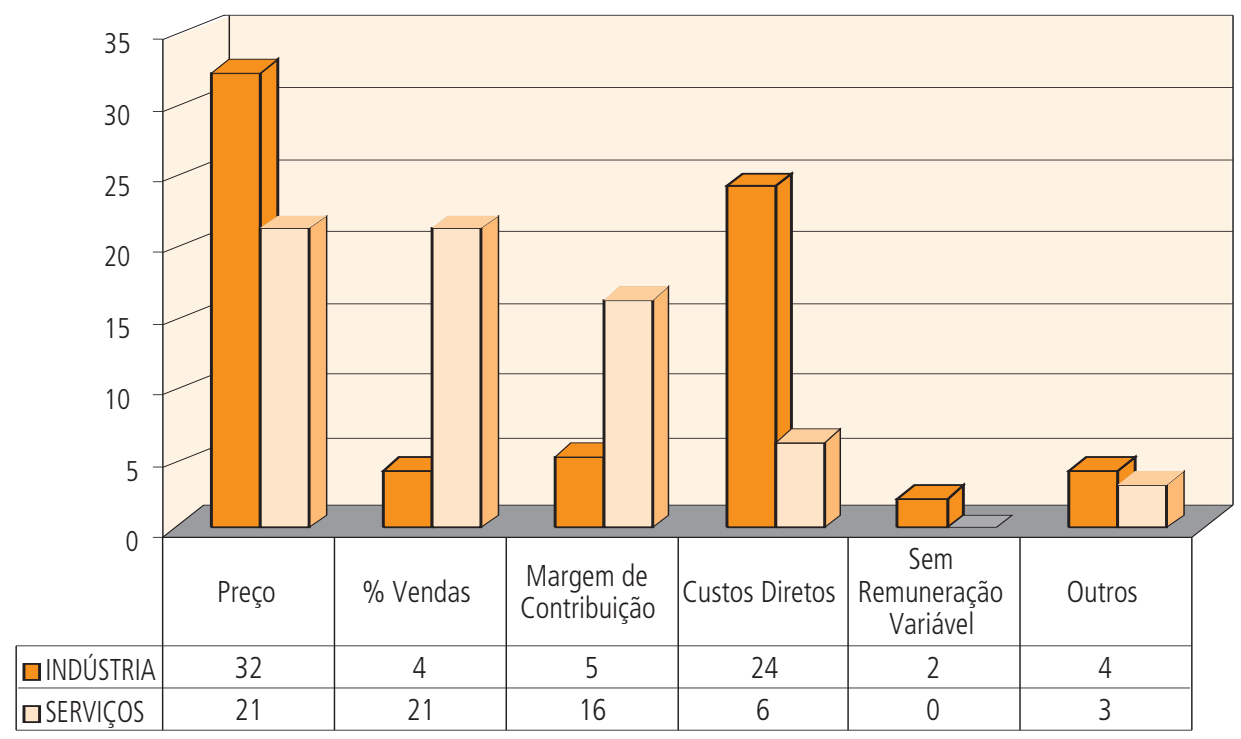

O Gráfico 6 mostra que há uma interpretação diferenciada entre o entendimento dos dois grupos pesquisados quanto à remuneração. A indústria evidencia sua preferência por dois sistemas de remuneração:

I) pelo pagamento de remuneração variável como função direta de um percentual sobre o valor do contrato ou

2) pela divisão entre contratante e fornecedor do valor correspondente ao custo direto de materiais e serviços que o contrato de manutenção conseguir reduzir. Os representantes dos fornecedores de serviços dividem-se em três sistemas:

I) percentual sobre o valor do contrato (como a indústria); 
2) percentual sobre o faturamento adicionado à empresa contratante em função das ações implementadas pelo fornecedor no contrato; ou

3) rateio percentual da margem de contribuição sobre a produção agregada pelo contrato.

Fica evidente nessa análise o comportamento protecionista das indústrias e agressivo dos fornecedores, que, mesmo com auto-avaliações críticas constatadas em questões anteriores, acreditam em contratos ousados a ponto de não possuir limitadores de ganhos e perdas.

\subsection{BLOCO 6 - PERCEPÇÃO DA MATURIDADE E PREPARO}

Este bloco de questões procurou testar diretamente a suposição de que nem os clientes industriais nem os fornecedores especializados de manutenção estariam adequadamente preparados para desenvolvimento de contratos de remuneração variável baseados em performance.

O Gráfico 7 não deixa dúvidas quanto ao entendimento dos gestores de cada setor em relação ao assunto. Do setor industrial, 90\% dos entrevistados consideram que o fornecedor de serviços não está preparado e nem mesmo a auto-avaliação do setor industrial é diferente, pois 79\% desse grupo considera que a indústria também não está adequadamente preparada para o modelo de performance.

\section{GRÁFICO 7}

\section{AVALIAÇÃO DO CENÁRIO PARA CONTRATOS DE PERFORMANCE}

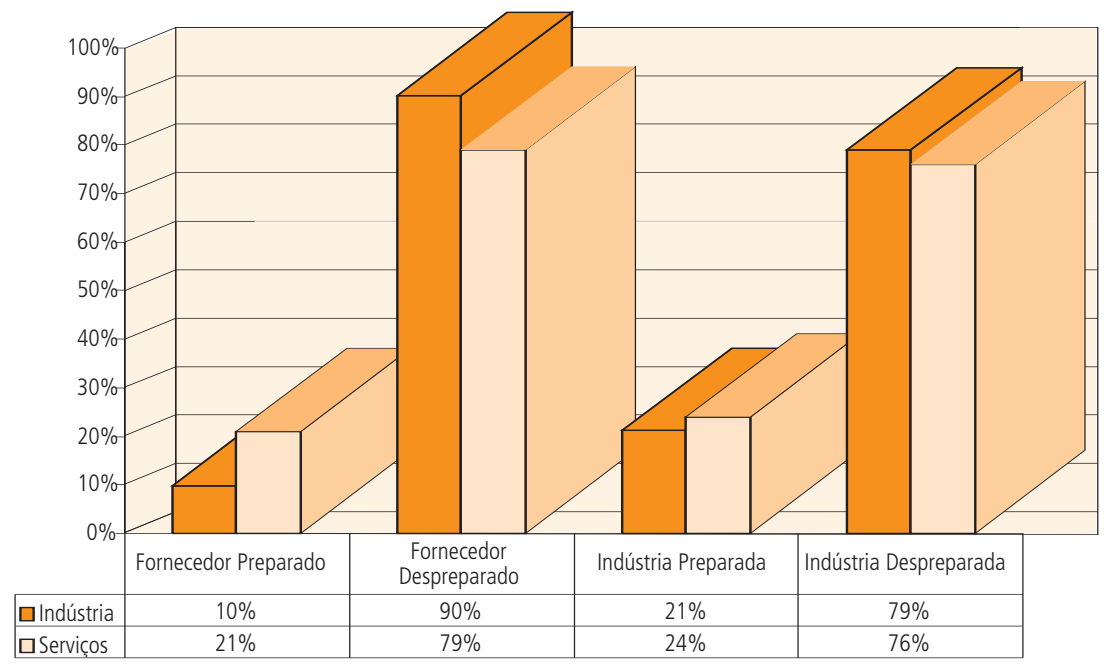

A avaliação do setor de serviços não é diferente: $79 \%$ considera o fornecedor não preparado e $76 \%$ considera a indústria não preparada. A fim de complementar a 
análise, o Gráfico 8 mostra a auto-avaliação dos entrevistados em relação ao conhecimento da ferramenta análise de risco, em que $84 \%$ do setor industrial e 9I\% dos prestadores de serviço consideram-se sem nenhum conhecimento (ou com apenas conhecimento básico das ferramentas de análise de risco). Isso já seria de esperar em países em desenvolvimento, mas a situação pode ser revertida em países mais industrializados.

\section{GRÁFICO 8}

\section{CONHECIMENTO DE ANÁLISE DE RISCO}

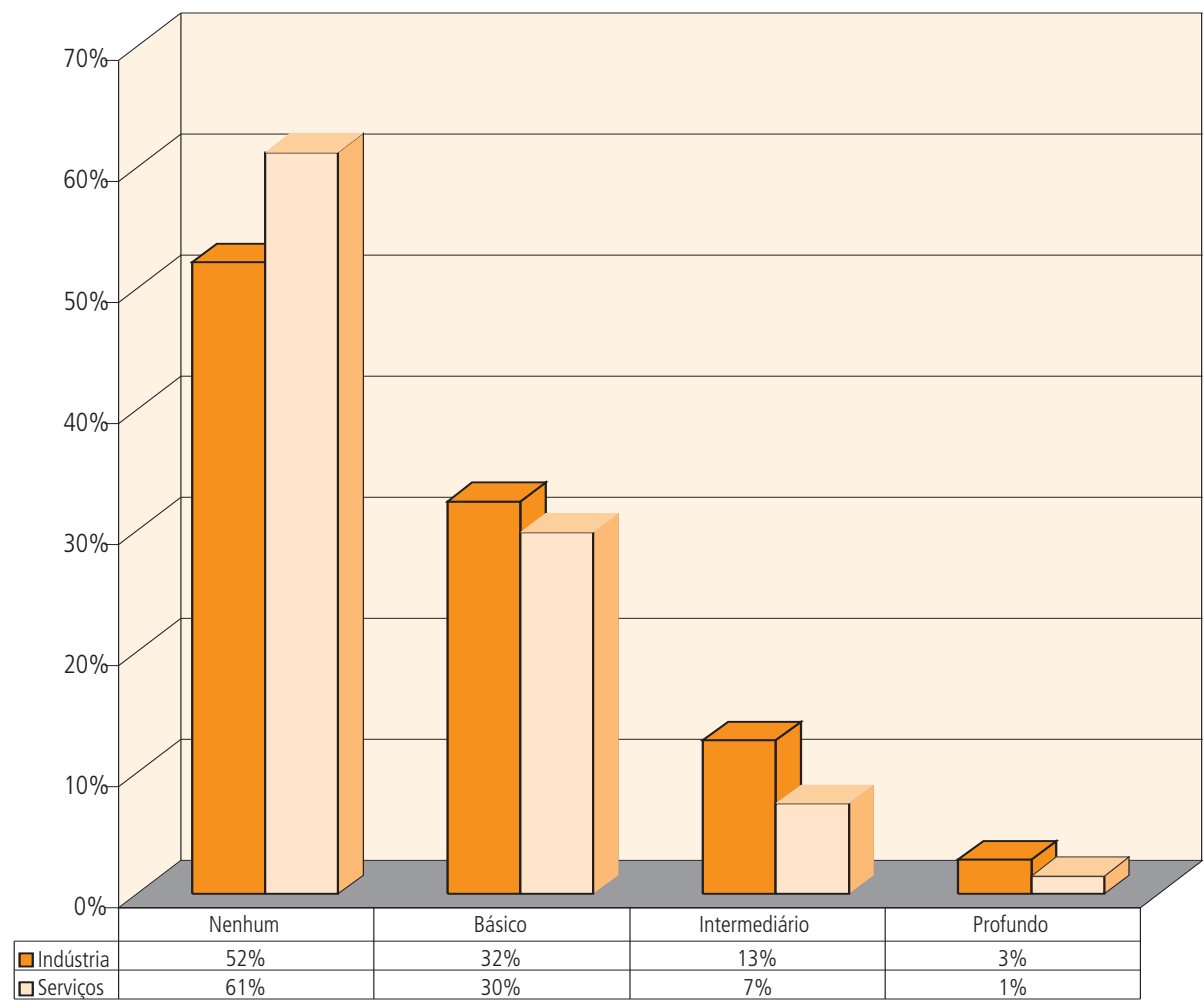

\subsection{BLOCO 7 - FATORES CRÍTICOS DE SUCESSO NO MODELO DE PERFORMANCE E RISCO}

Este bloco englobou 20 questões em que o entrevistado foi solicitado a avaliar os fatores críticos de sucesso para o desenvolvimento de um novo modelo de contrato, baseado em performance e risco, com o comprometimento das empresas. Entre as avaliações realizadas, os dez fatores com maior avaliação "importante" ou "muito importante" foram listadas na Tabela I, em ordem de preferência. 
A consolidação das avaliações dos prestadores de serviços e dos gestores das indústrias, a partir da Tabela I, demonstra que ocorreu a mesma escolha de fator crítico de sucesso para nove dos dez itens ordenados, entre um conjunto de 2I.

Essa constatação induz à seguinte conclusão: apesar de perspectivas e tratamento de dados distintos, a visão dos dois grupos é similar em termos de objetivos e dos valores necessários para que eles sejam alcançados.

\section{TABELA I}

\begin{tabular}{rl|l}
\hline \multicolumn{2}{c|}{ LISTAGEM ORDENADA DOS FATORES CRITICOS DE S UCES SO } \\
\hline & INDÚSTRIA & \multicolumn{1}{c}{ SERVIço } \\
\hline $\mathbf{1}$ & $\begin{array}{l}\text { Encontrar o melhor modelo de } \\
\text { remuneração variável para a indústria }\end{array}$ & Análise financeira das empresas \\
\hline $\mathbf{2}$ & Qualificação técnica do fornecedor & Qualificação técnica do fornecedor \\
\hline $\mathbf{3}$ & Definição clara de metas e objetivos & Definição clara de metas e objetivos \\
\hline $\mathbf{4}$ & Análise financeira das empresas & $\begin{array}{l}\text { Encontrar o melhor modelo de } \\
\text { remuneração variável para a indústria }\end{array}$ \\
\hline $\mathbf{5}$ & Preparação do ambiente interno da indústria & $\begin{array}{l}\text { Preparação do ambiente interno } \\
\text { da indústria }\end{array}$ \\
\hline $\mathbf{6}$ & Gestão da qualidade & Engenharia de manutenção \\
\hline $\mathbf{7}$ & Engenharia de manutenção & Analisar aspectos legais \\
\hline $\mathbf{8}$ & Gestão de segurança, saúde e meio ambiente & $\begin{array}{l}\text { Gestão de segurança, saúde e } \\
\text { meio ambiente }\end{array}$ \\
\hline $\mathbf{9}$ & Analisar aspectos legais & Política de Remuneração Salarial \\
\hline $\mathbf{1 0}$ & Experiência comprovada em contratos anteriores & Gestão da qualidade \\
\hline
\end{tabular}

\section{CONCLUSÕES}

Nos modelos atuais de contratação de manutenção (que podem ser estimados como sendo formas híbridas entre práticas passadas e práticas emergentes), o fornecedor de serviços vivencia um período transitório, em que deve participar de um mercado que demanda contratos desde venda de taxa-hora ("homemhora") até contratos com modelos de performance e risco.

Quando o fornecedor se auto-declara não preparado para atender à demanda por contratos de performance, ele é influenciado principalmente pela certeza da mudança cultural necessária, pelo modelo de formação de preço corrente - que não admite a consideração de riscos -, pelo receio de não ter em seus quadros gerentes suficientemente qualificados para administrar um contrato não como uma prestação de serviços, no modelo tradicional, mas como uma aliança estratégica, pela sua pouca habilidade ou desconhecimento do gerenciamento de riscos etc. 
Em paralelo, como discutido anteriormente, a migração de conceitos deve ser feita num ambiente de mercado agressivo, em que resultados financeiros precisam ser apresentados continuamente. Como investir profundamente tempo, dinheiro, energia - numa mudança de conceito e ao mesmo tempo apresentar resultados lucrativos é o paradoxo gerencial dos gestores profissionais das empresas especialistas de manutenção. Aqueles que solucionarem esse problema de maneira efetiva e com maior agilidade poderão se transformar de fato nos "primeiros entrantes" desta nova onda de contratações, com margens de lucro significativamente superiores.

Por outro lado, fica evidente (na primeira parte da pesquisa) que os gestores do segmento industrial são solicitados a desenvolver uma avaliação da situação atual de contratação de serviços de manutenção, que eles constantemente vivem um dilema conceitual: se por um lado concordam com a necessidade de contratos de performance e demandam esse modelo sistematicamente, por outro relatam que sua forma de contratação ainda é fortemente influenciada por modelos baseados em preço, principalmente contratações por preço unitário.

Assim como no setor de serviços, os gestores do segmento industrial reconhecem a necessidade de estabelecimento de alianças estratégicas de longo prazo, com cláusulas de remuneração por performance. Dessa maneira, pretendem ter fornecedores como aliados de longo prazo na cadeia de valor, comprometidos com a produtividade das plantas e partícipes da construção de novos modelos de relacionamento. Esses gestores traem-se, no entanto, quando são questionados a dar sua opinião pessoal quanto à participação de mão-de-obra contratada na gestão e execução de manutenção. Dos entrevistados, $44 \%$ responderam que sua preferência é por mão-de-obra própria, com mão-de-obra contratada somente para atividades de apoio. Outro indicador que merece ser estudado relaciona-se ao método de pagamento de remuneração baseado em performance, em que os entrevistados desse setor informaram que têm preferência por remunerar com base em um percentual fixo do valor do contrato ou com o rateio da economia - na conta custos diretos de manutenção - proporcionada pelo prestador de serviços. Essas duas formas, apesar de representarem um avanço em relação ao formato tradicional, estão ainda distantes de serem fatores financeiros incentivadores para que os fornecedores de serviços invistam na tecnologia necessária para obtenção dos melhores contratos possíveis.

Nota: os questionários aplicados, contendo os 50 itens avaliados em cada empresa, estão disponíveis para os leitores, bastando apenas contatar o segundo autor do trabalho. 


\section{REFERÊNCIAS}

HILL, W. Der Stellen vert der unternechmensberatung für die unternehmensführung. In: MITCHELL, V. M. Segmenting purchasers of organizational professional services: a risk-based approach, p. I7I-I88, I990.

KAHNEMAN, D.; TVERSKY, A. Choices, values, and frames. Cambridge: Cambridge University Press, 2000.

MARTIN, H. H. Contracting out maintenance and a plan for future research. Journal of Quality in Maintenance Engineering, v. 3, n. 2, p. 8I-90, I997.

MITCHELL, V. Segmenting purchasers of organizational professional services: a risk-based approach. The Journal of Services Marketing I2(2), p. 83-97, I998.

NORMANN, R. Service management. New York: John Wiley, I99I.

OLIVA, R.; KALLENBERG, R. Managing the transition from products to services. International Journal of Service Industry Management, v. I4, n. 2, p. I60-I72, 2003.

RAFTERY, J. Risk Analysis in project management. London: E \& FN Spon, I994.

SCHLEGELMICH, B. B.; DIAMANTO POULOS, A.; MOORE, S. A. The market for management consulting in Britain: an analysis of supply and demand. Management Decision, v. 30, n. 2, p. 46-54, I992. STUART, F. I. The influence of organizational culture and internal politics on new service design and introduction. International Journal of Service Industry Management, v. 9, n. 5, p. 469-485, I998. WIDEMAN, R. M. Project and program risk management: a guide to managing project risks and opportunities. North Carolina: Project Management Institute, I992.

YORKE, D. Developing an interactive approach to the marketing of professional services. In: FORD, D. (Ed.). Interaction, relationships, networks. London: Sage Publications,

TR A MITAÇ A O

Recebido em 21/06/2004

Aprovado em 15/10/2004 
Copyright of Revista de Administração Mackenzie is the property of Universidade Presbiteriana Mackenzie, RAM-Revista de Administracao Mackenzie and its content may not be copied or emailed to multiple sites or posted to a listserv without the copyright holder's express written permission. However, users may print, download, or email articles for individual use. 